\title{
Investigation of crystal structure and ionic transport in a scandium-based NASICON material by neutron powder diffraction
}

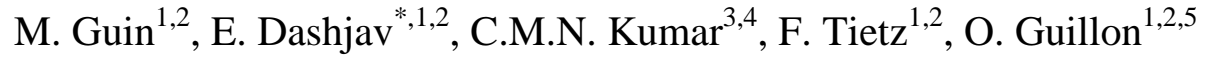

${ }^{1}$ Forschungszentrum Jülich GmbH, Institute of Energy and Climate Research (IEK-1): Materials Synthesis and Processing, D-52425 Jülich, Germany

${ }^{2}$ Helmholtz-Institute Münster, Forschungszentrum Jülich GmbH, D-52425 Jülich, Germany

${ }^{3}$ Forschungszentrum Jülich GmbH, Jülich Centre for Neutron Science (JCNS), Outstation at SNS, Oak Ridge National Laboratory, Oak Ridge, Tennessee 37831, United States

${ }^{4}$ Chemical and Engineering Materials Division, Oak Ridge National Laboratory, Oak Ridge, Tennessee 37831, United States

${ }^{5}$ Jülich Aachen Research Alliance, JARA-ENERGY, Germany

\begin{abstract}
A study of the series $\mathrm{Na}_{3+\mathrm{x}} \mathrm{Sc}_{2} \mathrm{Si}_{\mathrm{x}} \mathrm{P}_{3-\mathrm{x}} \mathrm{O}_{12}(0<\mathrm{x}<0.8)$ revealed very high ionic conductivity values at room temperature. The structural investigation of the substitutional disorder and position of the very mobile $\mathrm{Na}^{+}$ions in the crystal structure is the key to understanding the structure-property-chemical bonding relationships. Therefore neutron powder diffraction was carried out at 300 and $100 \mathrm{~K}$ on $\mathrm{Na}_{3.4} \mathrm{Sc}_{2} \mathrm{Si}_{0.4} \mathrm{P}_{2.6} \mathrm{O}_{12}$ to refine the structural parameters and to elucidate the $\mathrm{Na}^{+}$distribution in the crystal structure.
\end{abstract}

The refinement of the structure revealed that two phases are present, one rhombohedral Si-rich phase and one monoclinic $\mathrm{Na}_{3} \mathrm{Sc}_{2} \mathrm{P}_{3} \mathrm{O}_{12}$ phase. The ratio of the two phases is 1:1 and they possess similar lattice parameters. The hopping distances of the $\mathrm{Na}^{+}$ions and the size of the bottleneck for $\mathrm{Na}^{+}$ conduction were calculated and explained the high conductivity of the sample.

\section{Introduction}

The search for high sodium ion conduction in ceramic materials already focused on the class of NASICON-type ionic conductors in the late 1970s [1]. Very recently, very high conductivity values were achieved with this class of ceramic materials [2,3] giving new impetus for their use as solid-state electrolytes in low-temperature sodium batteries $[3,4,5]$. In order to understand the high conductivity in this class of ceramic electrolyte materials, a compositional guideline for high ionic conduction was

\footnotetext{
* Corresponding author. Tel.: +49 2461 61-4596; Fax: +49 2461 61-2455; E-mail: e.dashjav@fzjuelich.de
}

Keywords: neutron diffraction, NASICON, crystal structure, ionic conductivity 
proposed using available literature data [6]. This revealed that high ionic conductivity can be reached when the size of the $\mathrm{M}$ cation in the general formula $\mathrm{AM}_{2}\left(\mathrm{PO}_{4}\right)$ is close or equal to the size of sixfold coordinated $\mathrm{Zr}^{4+}\left(0.72 \AA\right.$ [7]). In addition, using aliovalent substitution of $\mathrm{P}$ with $\mathrm{Si}\left(\mathrm{Na}_{1+x} \mathrm{M}_{2}^{I V} \mathrm{Si}_{x} P_{3-}\right.$ $\left.{ }_{x} \mathrm{O}_{12}\right)$ and/or on the M-site $\left(\mathrm{Na}_{1+x+y} M_{2-y}^{I V} M_{y}^{I I I} \mathrm{Si}_{x} \mathrm{P}_{3-x} \mathrm{O}_{12}\right)$ and assuring electroneutrality by changing the amount of Na per formula unit, the optimal $\mathrm{Na}$ concentration was found to be around 3.2-3.5 mole per formula unit.

Using this guideline, the solid solutions $\mathrm{Na}_{3+\mathrm{x}} \mathrm{Sc}_{2} \mathrm{Si}_{\mathrm{x}} \mathrm{P}_{3-\mathrm{x}} \mathrm{O}_{12}$ [8] and $\mathrm{Na}_{3+\mathrm{x}} \mathrm{Sc}_{\mathrm{x}} \mathrm{Zr}_{2-\mathrm{x}} \mathrm{Si}_{2} \mathrm{PO}_{12}$ [2,9,10] were studied and maximum conductivity values were obtained for $x=0.4$ in both series [2]. In order to understand the structure-property-chemical bonding relationships, detailed crystallographic data are needed. In [8], preliminary X-ray diffraction (XRD) data were used for the solid solution $\mathrm{Na}_{3+\mathrm{x}} \mathrm{Sc}_{2} \mathrm{Si}_{\mathrm{x}} \mathrm{P}_{3-\mathrm{x}} \mathrm{O}_{12}$ but the $\mathrm{Si}$ and $\mathrm{P}$ atoms could not be distinguished and the position and site occupancy of the very mobile $\mathrm{Na}$ atoms was only determined with limited accuracy.

In this work, the highly conductive $\mathrm{Na}_{3.4} \mathrm{Sc}_{2} \mathrm{Si}_{0.4} \mathrm{P}_{2.6} \mathrm{O}_{12}$ was further investigated using neutron powder diffraction allowing the more accurate refinement of the $\mathrm{Na}, \mathrm{Si}$ and $\mathrm{P}$ atoms. In addition, measurements were also carried out at $100 \mathrm{~K}$ to reduce the mobility of $\mathrm{Na}^{+}$ions in the structure for better determination of positions and site occupancy factors.

\section{Experimental}

$\mathrm{Na}_{3.4} \mathrm{Sc}_{2} \mathrm{Si}_{0.4} \mathrm{P}_{2.6} \mathrm{O}_{12}$ was synthesized by a conventional solid-state reaction using a stoichiometric amount of $\mathrm{NH}_{4} \mathrm{H}_{2} \mathrm{PO}_{4}$ (Merck KGaA, $99 \%$ ), $\mathrm{Sc}_{2} \mathrm{O}_{3}$ (Projector GmbH, $99.5 \%$ ), $\mathrm{Na}_{2} \mathrm{CO}_{3}$ (Alfa Aesar $\mathrm{GmbH} \& \mathrm{Co} \mathrm{KG}, 99.5 \%$ ), and $\mathrm{SiO}_{2}$ (Alfa Aesar $\mathrm{GmbH} \& \mathrm{Co} \mathrm{KG}, 99.8 \%$ ). The mixture was heated at $300 \mathrm{~K} \mathrm{~h}^{-1}$ to $1173 \mathrm{~K}$ for $4 \mathrm{~h}$. The calcined powder was ground, then annealed at $1553 \mathrm{~K}$ for $20 \mathrm{~h}$. The obtained powder was milled in ethanol with $\mathrm{ZrO}_{2}$ milling balls. After drying, the material was annealed again at $1373 \mathrm{~K}$ to eliminate traces of water or $\mathrm{CO}_{2}$ on the sample. The powder was stored in an argon-filled glove box until used for further processing. For sample preparation, the powder was pressed into pellets and sintered at $1553 \mathrm{~K}$ for $10 \mathrm{~h}$.

The stoichiometry of the powder was controlled by inductively coupled plasma optical emission spectroscopy (ICP-OES). $10 \mathrm{mg}$ of powder was mixed with $0.25 \mathrm{mg}$ lithium borate in a platinum crucible and heated for $0.5 \mathrm{~h}$ at $1273 \mathrm{~K}$. The liquefied material was dissolved in $30 \mathrm{~mL} \mathrm{HCl} \mathrm{(5 \% )} \mathrm{and}$ made up to $50 \mathrm{~mL}$ volume with distilled water. The measurement was carried out using the Thermo Scientific iCAP7600 spectrometer with optical scale and CID semiconductor detector, axial und radial reflection, and wavelengths between $166 \mathrm{~nm}$ and $847 \mathrm{~nm}$. 
Neutron diffraction data were collected at $100 \mathrm{~K}$ and $300 \mathrm{~K}$ on the time-of-flight (TOF) diffractometer POWGEN at the Spallation Neutron Source in Oak Ridge National Laboratory. One set of data was collected for each temperature in the range of TOF from $9716 \mu$ s to $140000 \mu$ s (corresponding to $d$ spacing between 0.3 and $6.2 \AA$ ) with the centre wavelength of $1.333 \AA$. The crystallographic data were refined using the software Jana 2006 [11]. The background was fitted by manually set points using a polynomial interpolation and the peak profiles were modelled using pseudo-Voigt functions with back-to-back exponentials. The quality of the fitting was checked with the indicators $R_{p}$ (R-pattern), $R_{w p}$ (R-weighted pattern) and GoF (goodness of fit).

After sintering at $1553 \mathrm{~K}$, the density of the pellets was determined using the Archimedes method and was approximately $93 \%$ of theoretical density. The conductivity of these pellets was measured in air as described earlier $[2,8]$ with a multi-potentiostat VMP-300 from Bio-Logic SAS, France. Gold was used as the blocking electrodes sputtered on both sides of the pellets. The frequency range used was $1 \mathrm{~Hz}-7 \mathrm{MHz}$ at intervals of 20 points per decade with an amplitude of $50 \mathrm{mV}$.

\section{Results}

\section{Le Bail profile fitting}

The profile fitting was carried out using the refined unit cell parameters obtained from the XRD pattern of $\mathrm{Na}_{3.4} \mathrm{Sc}_{2} \mathrm{Si}_{0.4} \mathrm{P}_{2.6} \mathrm{O}_{12}$, which showed only one rhombohedral phase with space group $R \overline{3} c$ and less than $3 \%$ of a monoclinic phase with space group $C 2 / c$, a structural subgroup of the first phase [8]. However, the refinement of the profile parameters of the neutron diffraction data with space group $R \overline{3} c$ alone did not result in satisfactory residuals $\left(G o F / R_{p} / R_{w p}=4.4 / 6.4 / 3.8\right.$ at $\left.100 \mathrm{~K}\right)$ and the inspection of peak profiles revealed small broadenings and shoulders. Therefore the second monoclinic phase was added. The final quality of the fitting was $G o F / R_{p} / R_{w \mathrm{p}}=2.11 / 3.86 / 1.9$ at $100 \mathrm{~K}$ and 1.48/2.87/1.28 at $300 \mathrm{~K}$. The Le Bail fitting clearly revealed that the powder contains a mixture of monoclinic and rhombohedral phases.

\section{Rietveld refinement}

The Rietveld method was used to refine the atomic parameters and isotropic thermal parameters. The zero shift and sample displacement parameter were kept the same for both $100 \mathrm{~K}$ and $300 \mathrm{~K}$ temperatures. Using XRD, it was not possible to refine the occupancy of $\mathrm{P}$ and Si because of their similar atomic scattering factors. In contrast, all atoms can be readily distinguished from each other with neutron scattering because of their different nuclear scattering lengths, especially Si and $\mathrm{P}$ with $4.149 \mathrm{fm}$ and $5.130 \mathrm{fm}$, respectively [12].

The occupational parameters of the $\mathrm{P}, \mathrm{Si}$ and $\mathrm{Na}$ atoms were then refined step by step with respect to their thermal displacement and interatomic distances. 
For both temperatures Si was found to be only present in the rhombohedral phase. The phase fractions at $300 \mathrm{~K}$ and $100 \mathrm{~K}$ are similar within the range of standard deviation - 50\% rhombohedral and $50 \%$ monoclinic. Considering the nominal composition of the powder and assuming the absence of additional phases, the $\mathrm{P} / \mathrm{Si}$ ratio was constrained at 2.2/0.8 in the rhombohedral phase.

Table 1: Crystallographic and structural data of both phases in $\mathrm{Na}_{3.4} \mathrm{Sc}_{2} \mathrm{Si}_{0.4} \mathrm{P}_{2.6} \mathrm{O}_{12}$ determined from neutron diffraction patterns. The values in bold numbers refer to the measurement at $100 \mathrm{~K}$.

\begin{tabular}{|c|c|c|}
\hline Phase & $\mathrm{Na}_{3.8} \mathrm{Sc}_{2} \mathrm{Si}_{0.8} \mathrm{P}_{2.2} \mathrm{O}_{12}$ & $\mathrm{Na}_{3} \mathrm{Sc}_{2} \mathrm{P}_{3} \mathrm{O}_{12}$ \\
\hline Formula weight $/ \mathrm{g} \cdot \mathrm{mol}^{-1}$ & 459.9 & 443.8 \\
\hline Crystal system & rhombohedral & monoclinic \\
\hline Space group, $Z$ & $R \overline{3} c, 6$ & $\mathrm{C} 2 / \mathrm{c}, 4$ \\
\hline Phase fraction / wt $\%$ & $\mathbf{5 2 ( 3 )} / 60(3)$ & $\mathbf{4 8}(\mathbf{3}) / 40(3)$ \\
\hline $\mathrm{a} / \AA$ & $\mathbf{8 . 9 8 8 4 ( 6 ) / 8 . 9 8 3 6 ( 2 )}$ & $\mathbf{1 5 . 5 4 1 2 ( 9 )} / 15.5489(8)$ \\
\hline $\mathrm{b} / \AA$ & & $\mathbf{8 . 9 7 8 3 ( 5 )} / 8.9819(4)$ \\
\hline $\mathrm{c} / \AA$ & 21.992(3) / 22.2313(4) & $\mathbf{9 . 0 3 3 0 ( 5 ) / 9 . 0 6 7 4 ( 3 )}$ \\
\hline$\beta /{ }^{\circ}$ & & 125.14(4) / 124.73(4) \\
\hline $\mathrm{V} / \AA^{3}$ & 1538.7(2)/ 1553.8(6) & 1030.7(11)/ 1040.74(10) \\
\hline$r_{\mathrm{c} .} / \mathrm{g} \cdot \mathrm{cm}^{-3}$ & $\mathbf{2 . 9 7 7 9} / 2.9489$ & $\mathbf{2 . 8 6 0 0} / 2.8325$ \\
\hline TOF range $/ \mu$ s & \multicolumn{2}{|c|}{$9716-140000$} \\
\hline Refinement method & \multicolumn{2}{|c|}{ full matrix least square against $\mathrm{F}^{2}$} \\
\hline Data points ; number of parameters & \multicolumn{2}{|c|}{$\mathbf{2 8 6 1} ; \mathbf{7 8} / 2861 ; 77$} \\
\hline $\mathrm{R}_{\mathrm{p}} ; \mathrm{R}_{\mathrm{wp}} ; \mathrm{GOF}$ (all data) & \multicolumn{2}{|c|}{$6.20 ; 4.07 ; 4.76 / 5.95 ; 3.71 ; 4.34$} \\
\hline
\end{tabular}

Refinement of site occupation factors for Na sites resulted in a nearly charge-balanced formula. In the final cycle of the refinement, the total $\mathrm{Na}$ content was fixed to give a strictly electron-neutral formula. For both temperatures, the refinement of all positional, occupation, and thermal displacement parameters led to the following formulas: $\mathrm{Na}_{3} \mathrm{Sc}_{2} \mathrm{P}_{3} \mathrm{O}_{12}$ for the monoclinic phase and $\mathrm{Na}_{3.8} \mathrm{Sc}_{2} \mathrm{Si}_{0.8} \mathrm{P}_{2.2} \mathrm{O}_{12}$ for the rhombohedral phase. At $300 \mathrm{~K}$, the rhombohedral phase contains 3 Wyckoff positions for $\mathrm{Na}$ as described by Guin et al. [8], where the $\mathrm{Na}(3)$ position represents a displacement of the $\mathrm{Na}(2)$ position. At $100 \mathrm{~K}$, the sodium ions are less mobile and the $\mathrm{Na}(3)$ position was unoccupied. Nevertheless, the $\mathrm{Na}(2)$ site was refined with anisotropic displacement parameters leading to ellipsoids. Table 1 shows the refinement values for both phases at $100 \mathrm{~K}$ and $300 \mathrm{~K}$ and the refined diffraction patterns are plotted in Figure 1. Atomic parameters and equivalent displacement parameters are given in Table 2 and Table 3, respectively. 

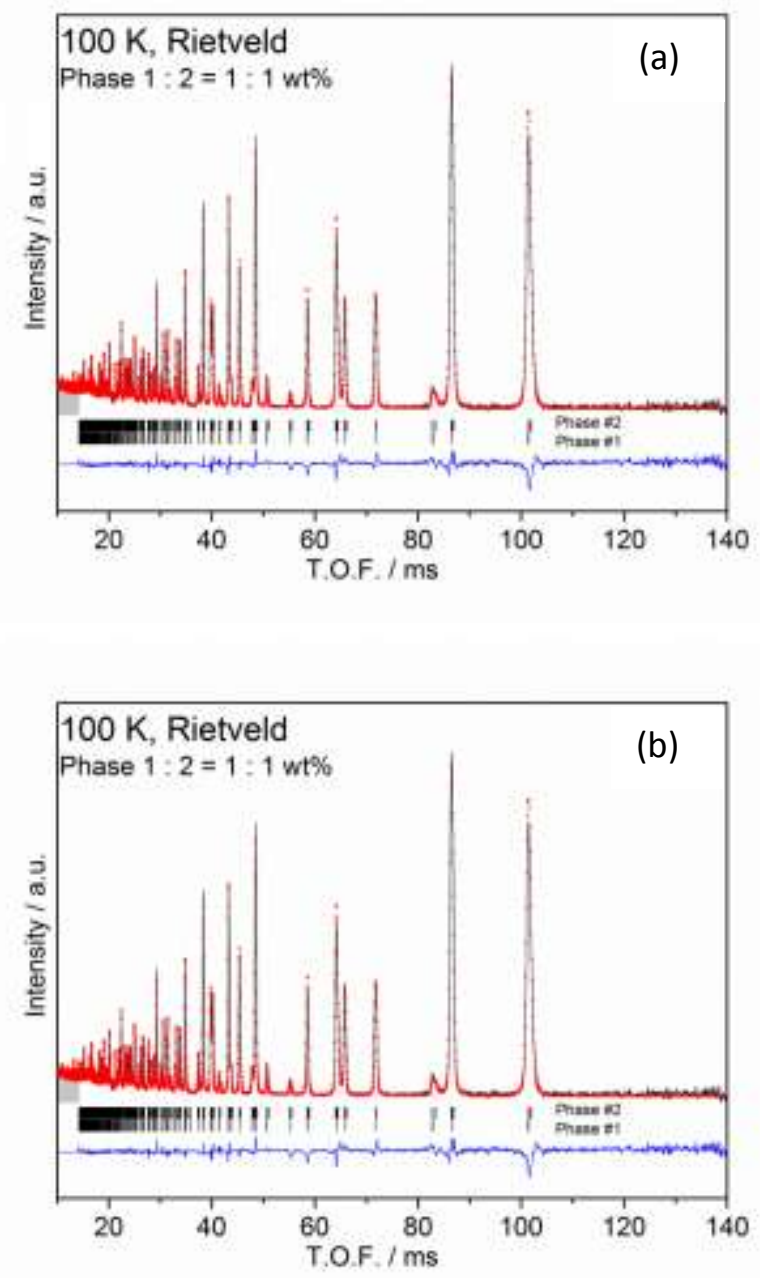

Figure 1: Rietveld refinement of TOF powder neutron diffraction patterns of $\mathrm{Na}_{3.4} \mathrm{Sc}_{2} \mathrm{Si}_{0.4} \mathrm{P}_{2.6} \mathrm{O}_{12}$. Calculated data are shown as red dots, observed ones as a black line and the difference between them is plotted as a blue line at the bottom. Vertical markers below the diffraction patterns indicate the positions of the Bragg reflections of both phases: Phase \#1: monoclinic, phase \#2: rhombohedral. 
Table 2: Positional and isotropic displacement parameters $\left[\AA^{2}\right]$ of the rhombohedral phase in nominal $\mathrm{Na}_{3.4} \mathrm{Sc}_{2} \mathrm{Si}_{0.4} \mathrm{P}_{2.6} \mathrm{O}_{12}$ (standard deviations are in brackets). The values in bold numbers refer to the measurement at $100 \mathrm{~K}$.

\begin{tabular}{|c|c|c|c|c|c|c|}
\hline Atom & Wyckoff position & Occupancy & $\mathrm{x}$ & $\mathrm{Y}$ & $\mathrm{z}$ & $\mathrm{U}_{\mathrm{eq}} / \mathrm{U}_{\text {iso }}$ \\
\hline \multicolumn{7}{|c|}{ Rhombohedral $\mathrm{Na}_{3.8} \mathrm{Sc}_{2} \mathrm{Si}_{0.8} \mathrm{P}_{2.2} \mathrm{O}_{12}$ phase } \\
\hline \multirow{2}{*}{$\mathrm{Sc}$} & \multirow{2}{*}{$12 c$} & 1 & $\mathbf{0}$ & $\mathbf{0}$ & $0.1480(3)$ & $0.0037(10)$ \\
\hline & & 1 & 0 & 0 & $0.1482(4)$ & \\
\hline \multirow{2}{*}{$\mathrm{P} / \mathrm{Si}$} & \multirow{2}{*}{$18 e$} & $0.73 / 0.27$ & $0.294(2)$ & $\mathbf{0}$ & 0.25 & $0.003(2)$ \\
\hline & & $0.73 / 0.27$ & $0.293(2)$ & 0 & 0.25 & \\
\hline \multirow{2}{*}{$\mathrm{O} 1$} & \multirow{2}{*}{$36 f$} & 1 & $0.193(2)$ & $-0.0185(17)$ & $0.1921(5)$ & $0.015(2)$ \\
\hline & & 1 & $0.188(2)$ & $-0.022(2)$ & $0.1936(6)$ & $0.029(4)$ \\
\hline \multirow{2}{*}{$\mathrm{O} 2$} & \multirow{2}{*}{$36 f$} & 1 & $0.1884(14)$ & $0.1717(14)$ & $0.0852(5)$ & $0.0082(17)$ \\
\hline & & 1 & $0.1915(19)$ & $0.1717(19)$ & $0.0878(5)$ & $0.017(3)$ \\
\hline \multirow{2}{*}{$\mathrm{Na} 1$} & \multirow{2}{*}{$6 b$} & 0.80 & $\mathbf{0}$ & $\mathbf{0}$ & $\mathbf{0}$ & \\
\hline & & 0.70 & 0 & 0 & 0 & \\
\hline \multirow{2}{*}{$\mathrm{Na} 2$} & \multirow{2}{*}{$18 e$} & 1 & $0.606(4)$ & $\mathbf{0}$ & 0.25 & \\
\hline & & 0.62 & $0.636(5)$ & 0 & 0.25 & $0.015(8)$ \\
\hline $\mathrm{Na} 3$ & $36 f$ & 0.20 & $0.985(12)$ & $0.690(11)$ & $0.943(4)$ & $0.015(8)$ \\
\hline \multicolumn{7}{|c|}{ Anisotropic displacement parameters } \\
\hline Atom & $\mathrm{U}_{11}$ & $\mathrm{U}_{22}$ & $\mathrm{U}_{33}$ & $\mathrm{U}_{12}$ & $\mathrm{U}_{13}$ & $\mathrm{U}_{23}$ \\
\hline $\mathrm{Sc}$ & $0.005(2)$ & $0.005(2)$ & $0.018(4)$ & $0.0024(10)$ & 0 & 0 \\
\hline \multirow{2}{*}{ Na1 } & $0.010(15)$ & $0.010(15)$ & $0.07(5)$ & $0.005(8)$ & $\mathbf{0}$ & $\mathbf{0}$ \\
\hline & $0.08(7)$ & $0.08(7)$ & $0.01(4)$ & $0.04(3)$ & 0 & 0 \\
\hline $\mathbf{N a 2}$ & $0.17(3)$ & $0.05(3)$ & $0.12(4)$ & $\mathbf{0 . 0 2 4 ( 1 3 )}$ & $0.036(14)$ & $0.07(3)$ \\
\hline
\end{tabular}

Table 3: Positional and isotropic displacement parameters $\left[\AA^{2}\right]$ of the monoclinic phase in nominal $\mathrm{Na}_{3.4} \mathrm{Sc}_{2} \mathrm{Si}_{0.4} \mathrm{P}_{2.6} \mathrm{O}_{12}$ (standard deviations are in brackets). The values in bold numbers refer to the measurement at $100 \mathrm{~K}$.

\begin{tabular}{|c|c|c|c|c|c|c|}
\hline Atom & Wyckoff position & Occupancy & $\mathrm{x}$ & $\mathrm{Y}$ & $\mathrm{Z}$ & $\mathrm{U}_{\mathrm{eq}} / \mathrm{U}_{\text {iso }}$ \\
\hline \multicolumn{7}{|c|}{ Monoclinic $\mathrm{Na}_{3} \mathrm{Sc}_{2} \mathrm{P}_{3} \mathrm{O}_{12}$ phase } \\
\hline \multirow{2}{*}{$\mathrm{Sc}$} & \multirow{2}{*}{$8 f$} & 1 & $0.3979(19)$ & $0.252(5)$ & $0.4438(17)$ & $0.0093(19)$ \\
\hline & & 1 & $0.3996(12)$ & $0.248(3)$ & $0.4481(16)$ & $0.012(2)$ \\
\hline \multirow{2}{*}{ P1 } & \multirow{2}{*}{$8 f$} & 1 & $0.644(5)$ & $0.391(7)$ & $0.733(7)$ & $0.013(10)$ \\
\hline & & 1 & $0.643(2)$ & $0.395(5)$ & $0.737(6)$ & $0.011(7)$ \\
\hline \multirow{2}{*}{ P2 } & \multirow{2}{*}{$4 e$} & 1 & 0.25 & $-0.046(14)$ & 0.75 & $0.02(2)$ \\
\hline & & 1 & 0.25 & $-0.072(8)$ & 0.75 & $0.021(12)$ \\
\hline \multirow{2}{*}{$\mathrm{O} 1$} & \multirow{2}{*}{$8 f$} & 1 & $0.544(4)$ & $0.353(7)$ & $0.603(6)$ & $0.016(9)$ \\
\hline & & 1 & $0.550(2)$ & $0.328(4)$ & $0.589(5)$ & $0.004(5)$ \\
\hline \multirow{2}{*}{$\mathrm{O} 2$} & \multirow{2}{*}{$8 f$} & 1 & $0.567(5)$ & $0.059(7)$ & $0.902(8)$ & $0.020(11)$ \\
\hline & & 1 & $0.573(3)$ & $0.036(6)$ & $0.944(6)$ & $0.030(9)$ \\
\hline \multirow{2}{*}{$\mathrm{O} 3$} & \multirow[b]{2}{*}{$8 \mathrm{f}$} & 1 & $0.674(4)$ & $0.371(7)$ & $0.958(6)$ & $0.019(10)$ \\
\hline & & 1 & $0.640(4)$ & $0.349(9)$ & $0.897(8)$ & $0.047(14)$ \\
\hline \multirow{2}{*}{$\mathrm{O} 4$} & \multirow{2}{*}{$8 \mathrm{f}$} & 1 & $0.336(4)$ & $0.428(7)$ & $0.241(5)$ & $0.005(8)$ \\
\hline & & 1 & $0.344(3)$ & $0.434(6)$ & $0.267(6)$ & $0.024(9)$ \\
\hline \multirow{2}{*}{ O5 } & \multirow{2}{*}{$8 \mathrm{f}$} & 1 & $0.575(4)$ & $0.142(7)$ & $0.234(6)$ & $0.007(8)$ \\
\hline & & 1 & $0.578(3)$ & $0.144(5)$ & $0.240(7)$ & $0.014(7)$ \\
\hline \multirow{2}{*}{ O6 } & \multirow{2}{*}{$8 \mathrm{f}$} & 1 & $0.755(4)$ & $0.169(7)$ & $0.226(5)$ & $0.012(11)$ \\
\hline & & 1 & $0.758(3)$ & $0.177(5)$ & $0.225(6)$ & $0.011(6)$ \\
\hline \multirow{2}{*}{$\mathrm{Na} 1$} & \multirow{2}{*}{$4 c$} & 0.61 & 0.25 & 0.25 & $\mathbf{0}$ & $0.01(2)$ \\
\hline & & 0.58 & 0.25 & 0.25 & 0 & $0.04(3)$ \\
\hline \multirow{2}{*}{$\mathrm{Na} 2$} & \multirow[b]{2}{*}{8} & 1 & $0.817(6)$ & $0.441(9)$ & $0.218(8)$ & $0.018(17)$ \\
\hline & & 0.95 & $0.808(5)$ & $0.466(9$ & $0.205(9)$ & $0.034(13)$ \\
\hline \multirow[t]{2}{*}{$\mathrm{Na} 3$} & \multirow{2}{*}{$4 e$} & 0.39 & 0.5 & $\mathbf{0 . 3 4}(3)$ & $\mathbf{0 . 2 5}$ & $\mathbf{0 . 0 1}(2)$ \\
\hline & & 0.5 & 0.5 & $0.43(3)$ & 0.25 & $0.034(13)$ \\
\hline
\end{tabular}




\section{Discussion}

\section{Structural relationship between the monoclinic and rhombohedral structure}

The monoclinic and rhombohedral structures of the NASICON materials were analysed and compared in detail by Colin et al. [13] for pure $\mathrm{Na}_{3} \mathrm{Sc}_{2}\left(\mathrm{PO}_{4}\right)_{3}$, where these structures occur after three different synthesis routes at different temperatures. The authors emphasized that synthesis conditions are critical for phase formation. The two crystal structures are closely related, and the main differences can be summarized as follows: The monoclinic structure presents (a) ordering of $\mathrm{Na}^{+}$ions/vacancies, (b) a slightly distorted crystal lattice, and (c) ordering of $\mathrm{PO}_{4}$ tetrahedra (in the rhombohedral structure they show rotational disorder).

In the present case, approximately equal amounts of monoclinic and rhombohedral phases are present in the same sample. The monoclinic phase does not contain any $\mathrm{Si}$, which is exclusively incorporated into the rhombohedral phase. Despite the different Si content and the different ionic radii for fourfoldcoordinated Si or P $(0.26 \AA$ and $0.17 \AA$ [7]), the molar volume of both phases is almost equal. This is in contrast to the behaviour observed by Guin et al. for the solid solution series [8], where the molar volume increases with increasing Si content. This shows that the synthesis conditions are indeed very important for the crystal structure obtained after the final heat treatment and that reproducible preparation requires very accurate adherence to the experimental conditions.

\section{Ordering of Na ions and pathway for the Na conduction}

The pathways of $\mathrm{Na}^{+}$ions in both the rhombohedral and monoclinic NASICON structure have already been described in the first report on NASICON material by Hong et al. [1,14]. The $\mathrm{Na}^{+}$ions jump from one position to the next through oxygen triangles (denoted as $\mathrm{T} 1$ and $\mathrm{T} 2$ ), the bottlenecks for $\mathrm{Na}^{+}$ conduction. For good $\mathrm{Na}^{+}$conductivity, the following conditions need to be met: (a) the $\mathrm{Na}-\mathrm{Na}$ distances should be close to $3.4 \AA$, which was found to be the optimum hopping distance [8] and (b) the triangle for this jump should be as large as possible.

In the rhombohedral phase, the conduction occurs from the $\mathrm{Na}(1)$ to the $\mathrm{Na}(2)$ position or its displacement, the $\mathrm{Na}(3)$ position, so that the sequence can be written as $\mathrm{Na}(1)-\mathrm{Na}(2)-\mathrm{Na}(1)$ and $\mathrm{Na}(1)-\mathrm{Na}(3)-\mathrm{Na}(1)$ at room temperature. One Na-polyhedra chain along which the $\mathrm{Na}^{+}$ions are mobile is shown in Figure $2 \mathrm{~b}$, where the $\mathrm{ScO}_{6}$ octahedra and $(\mathrm{P} / \mathrm{Si}) \mathrm{O}_{4}$ tetrahedra are not shown for the sake of clarity. The hopping distances for both pathways are summarized in Table 4. No other pathway can be considered because the hopping distances are not favourable $(<3 \AA$ or $>4 \AA$ ).

At $100 \mathrm{~K}$, the $\mathrm{Na}(3)$ position is not populated, but the thermal parameters of the atoms on $\mathrm{Na}(2)$ sites indicate a slight displacement towards this position (Figure 22a), which means that at low temperature the $\mathrm{Na}^{+}$mobility is reduced but both structure models are in agreement. In addition, at both $100 \mathrm{~K}$ and $300 \mathrm{~K}, \mathrm{Na}^{+}$hopping in the structure is isotropic and the $\mathrm{Na}(1)$ atoms are sixfold coordinated by $\mathrm{Na}(2)$ 
atoms resulting in a three-dimensional conduction path. At $100 \mathrm{~K}$, the $\mathrm{Na}(1)-\mathrm{Na}(2)$ atomic distance is reduced to $3.32 \AA$ (compared to $3.41 \AA$ at $300 \mathrm{~K}$ ) and the $\mathrm{Na}$ (2) position is fully occupied.

For the single-phase rhombohedral $\mathrm{Na}_{3.4} \mathrm{Sc}_{2} \mathrm{Si}_{0.4} \mathrm{P}_{2.6} \mathrm{O}_{12}$ material [8], the first pathway $\mathrm{Na}(1)-\mathrm{Na}(2)$ $\mathrm{Na}$ (1) corresponds to a jump length of $3.43 \AA$ and the second pathway $\mathrm{Na}(1)-\mathrm{Na}(3)-\mathrm{Na}(1)$ has alternate hopping distances of $2.95 \AA$ and $3.78 \AA$ at room temperature. These values do not represent any significant differences compared to the rhombohedral phase here in the two-phase sample (see Table 4). The T1 area for the first pathway, $5.23 \AA$ [8], is smaller than the value of $5.30 \AA$ in the corresponding phase of the two-phase sample.
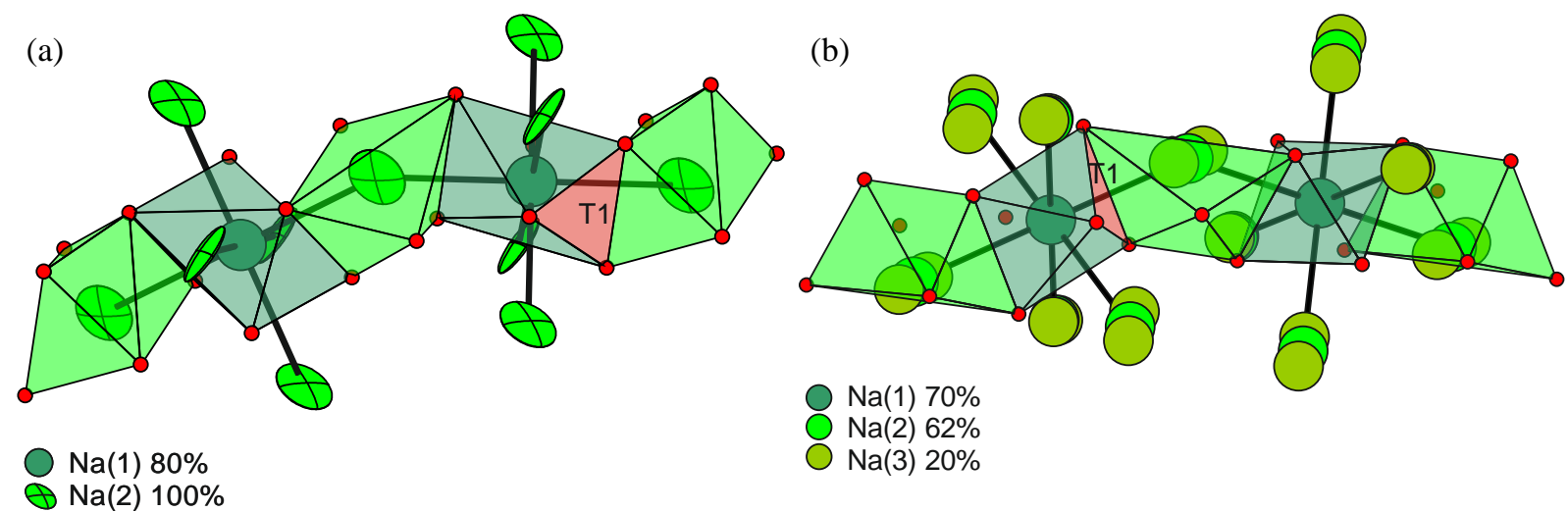

Figure 2: Connection of Na-polyhedra chains in $\mathrm{Na}_{3.8} \mathrm{Sc}_{2} \mathrm{Si}_{0.8} \mathrm{P}_{2.2} \mathrm{O}_{12}$. (a) represents the $\mathrm{Na}(1)-\mathrm{Na}(2)$ $\mathrm{Na}$ (1) structure cut-out at $100 \mathrm{~K}$, and (b) a model of disordered chains $\mathrm{Na}(3) / \mathrm{Na}(2)-\mathrm{Na}(1)-\mathrm{Na}(2) / \mathrm{Na}(3)$ at $300 \mathrm{~K} . \mathrm{O}^{2-}$ ions are located at the corners of the polyhedra (red spheres). In both figures the triangle $\mathrm{T} 1$ is drawn with pale red colour.

Table 4: Wyckoff positions and site occupancy for the $\mathrm{Na}^{+}$ions in the rhombohedral $\mathrm{Na}_{3.8} \mathrm{Sc}_{2} \mathrm{Si}_{0.8} \mathrm{P}_{2.2} \mathrm{O}_{12}$ phase and interatomic distances along the pathways for Na conduction.

\begin{tabular}{|c|c|c|c|}
\hline \multirow{2}{*}{$\mathrm{T}$} & \multirow{2}{*}{ Site occupancy } & \multicolumn{2}{|c|}{ Atomic distances along the pathway and $\mathrm{T} 1$ area } \\
\hline & & $\mathrm{Na}(1)-\mathrm{Na}(2)-\mathrm{Na}(1) / \mathrm{T} 1$ & $\mathrm{Na}(1)-\mathrm{Na}(3)-\mathrm{Na}(1) / \mathrm{T} 1$ \\
\hline $100 \mathrm{~K}$ & $\begin{array}{c}\mathrm{Na}(1) 6 b 80 \% \\
\mathrm{Na}(2) 18 e 100 \%\end{array}$ & 3.32(1) $\AA$ / 5.13 $\AA^{2}$ & 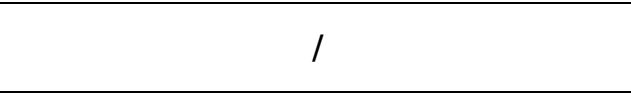 \\
\hline $300 \mathrm{~K}$ & $\begin{array}{c}\mathrm{Na}(1) 6 b 70 \% \\
\mathrm{Na}(2) 18 e 62 \% \\
\mathrm{Na}(3) 36 f 20 \%\end{array}$ & $3.41(3) \AA / 5.30 \AA^{2}$ & $3.00(10) \AA, 3.90(7) \AA / 5.30 \AA^{2}, 5.66 \AA^{2}$ \\
\hline
\end{tabular}

For monoclinic NASICON materials, there are three Wyckoff positions for the sodium ions. Similar to the rhombohedral structure, conduction occurs by jumping from the $\mathrm{Na}(1)$ to the $\mathrm{Na}(2)$ or $\mathrm{Na}(3)$ sites through oxygen triangles. The first pathway $\mathrm{Na}(1)-\mathrm{Na}(2)$ is similar to the case of the rhombohedral structure and is shown in Figure 3a, the second pathway is depicted in

Figure 3, while the interatomic distances are summarized in Table 5. 
For the single-phase monoclinic $\mathrm{Na}_{3} \mathrm{Sc}_{2}\left(\mathrm{PO}_{4}\right)_{3}$ at room temperature, the first pathway $\mathrm{Na}(1)-\mathrm{Na}(2)-$ $\mathrm{Na}$ (1) has a hopping distance of $3.48 \AA$ [13], the second pathway $\mathrm{Na}(1)-\mathrm{Na}(3)-\mathrm{Na}(1)$ corresponds to a rather long and thus unfavourable hopping distance of $4.31 \AA$. The area $\mathrm{T} 1$ for the pathway $\mathrm{Na}(1)$ $\mathrm{Na}(2)-\mathrm{Na}(1), 4.98 \AA^{2}$ [13] is smaller than the value of $5.36 \AA^{2}$ of the corresponding phase in the twophase sample (see Table 5).

(a)

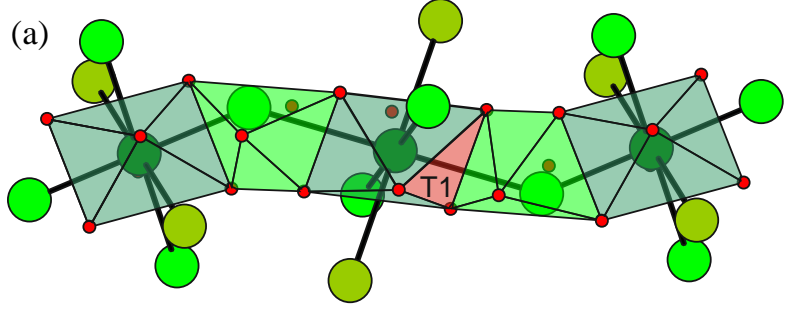

$\mathrm{Na}(1) 61 \% \quad 60 \%$

$\mathrm{Na}(2) \mathbf{1 0 0} \% 95 \%$

$\mathrm{Na}(3) 39 \% 50 \%$

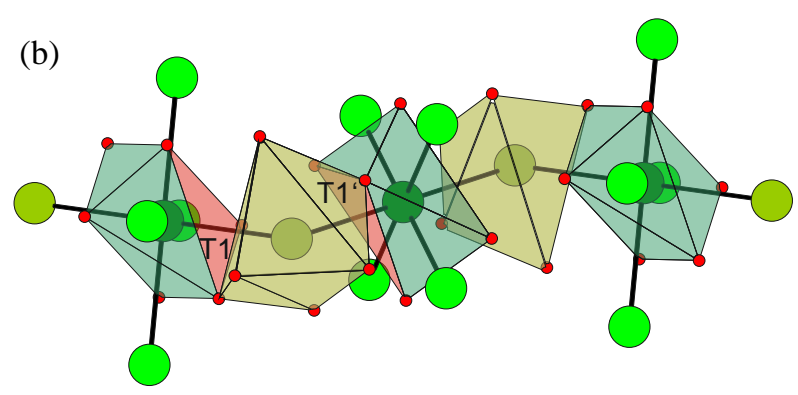

Figure 3: Edge-connected chains of polyhedra around $\mathrm{Na}$ atoms in $\mathrm{Na}_{3} \mathrm{Sc}_{2} \mathrm{P}_{3} \mathrm{O}_{12}$, (a) represents the chain $\mathrm{Na}(1)-\mathrm{Na}(2)-\mathrm{Na}(1)$ and (b) $\mathrm{Na}(1)-\mathrm{Na}(3)-\mathrm{Na}(1)$. The occupancy of the atomic positions is given in bold and normal letters for $100 \mathrm{~K}$ and $300 \mathrm{~K}$, respectively. $\mathrm{O}^{2-}$ ions are located at the corners of the polyhedra (red spheres). In both figures the triangle T1 (T1') is drawn with pale red colour.

Table 5: Wyckoff positions and site occupancy for the $\mathrm{Na}^{+}$ions in the monoclinic $\mathrm{Na}_{3} \mathrm{Sc}_{2} \mathrm{P}_{3} \mathrm{O}_{12}$ phase and interatomic distances along the pathways for $\mathrm{Na}$ conduction.

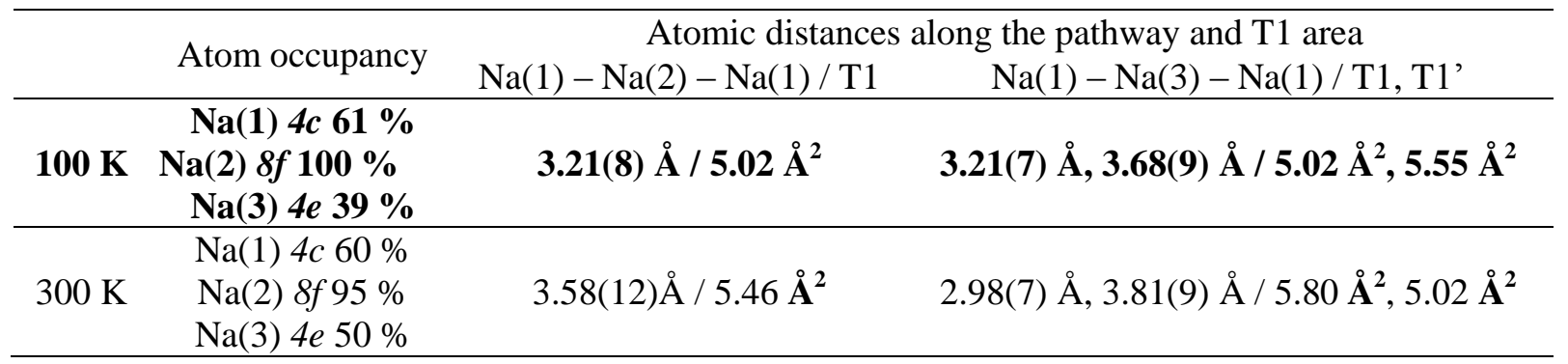

Conductivity of $\mathrm{Na}_{3.4} \mathrm{Sc}_{2} \mathrm{Si}_{0.4} \mathrm{P}_{2.6} \mathrm{O}_{12}$

The two-phase sample showed a total conductivity of $3.5 \times 10^{-4} \mathrm{~S} \mathrm{~cm}^{-1}$ at room temperature. This value is one order of magnitude higher than the conductivity reported for each composition of both phases. In fact, single-phase monoclinic $\mathrm{Na}_{3} \mathrm{Sc}_{2}\left(\mathrm{PO}_{4}\right)_{3}$ and single-phase rhombohedral $\mathrm{Na}_{3.8} \mathrm{Sc}_{2} \mathrm{Si}_{0.8} \mathrm{P}_{2.2} \mathrm{O}_{12}$ have a conductivity of $0.1-8.9 \times 10^{-5} \mathrm{~S} \mathrm{~cm}^{-1}[15,16,17,18,19]$ and $5.6 \times 10^{-5} \mathrm{~S} \mathrm{~cm}^{-1}$ [8] at room temperature, respectively. The wide spread of conductivity data for $\mathrm{Na}_{3} \mathrm{Sc}_{2}\left(\mathrm{PO}_{4}\right)_{3}$ (Figure 4) again reflects the significant influence of synthesis parameters, processing and the resulting microstructure on the materials properties. It is interesting to note that no slope changes induced by phase transitions (at about $330-370 \mathrm{~K}$ and $440-490 \mathrm{~K}$ for curves 2-6 in Figure 4) are observed when the $\mathrm{Na}_{3} \mathrm{Sc}_{2}\left(\mathrm{PO}_{4}\right)_{3}$ is 
substituted with Si. Similarly, phase transitions can be avoided, when the Sc-content is largely replaced by $\mathrm{Zr}$ (see curves 7-10 in Figure 4).

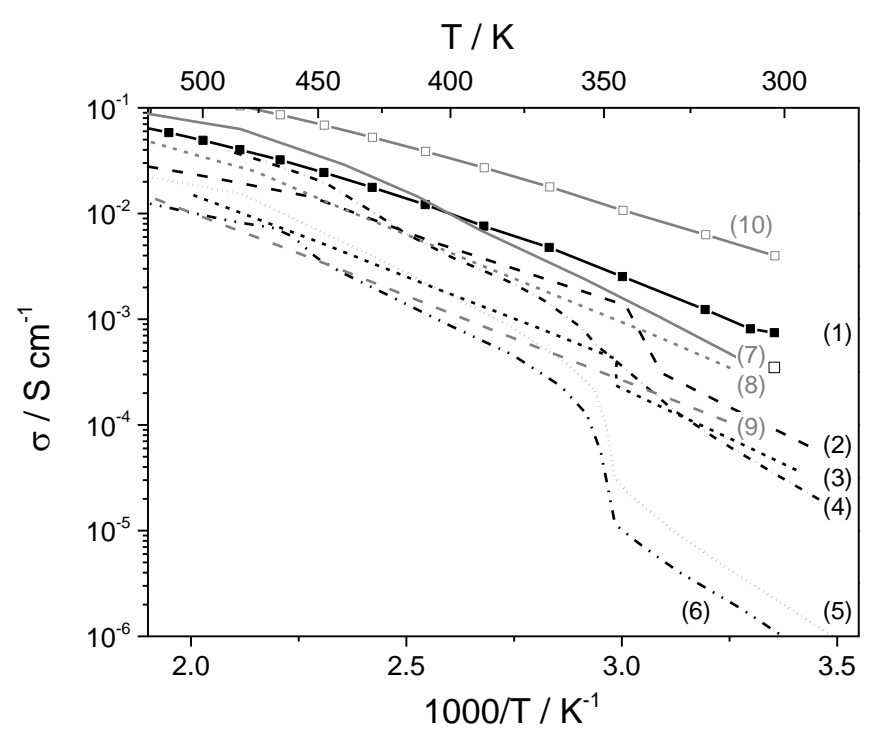

Figure 4: Ionic conductivity of $\mathrm{Na}_{3.4} \mathrm{Sc}_{2} \mathrm{Si}_{0.4} \mathrm{P}_{2.6} \mathrm{O}_{12}$ [8], curve (1), in comparison with measurements of $\mathrm{Na}_{3} \mathrm{Sc}_{2}\left(\mathrm{PO}_{4}\right)_{3}$ reported in [15] (curve 2), [16] (curve 3), [17] (curve 4), [18] (curve 5) and [19] (curve 6). The conductivity at room temperature of the sample investigated in this work is shown as an open square. Furthermore, the ionic conductivities of $\mathrm{Na}_{3+x+y} \mathrm{Sc}_{x} \mathrm{Zr}_{2-x} \mathrm{Si}_{y} \mathrm{P}_{3-y} \mathrm{O}_{12}$ materials are shown as grey curves: $\mathrm{Na}_{3} \mathrm{Sc}_{0.2} \mathrm{Zr}_{1.8} \mathrm{Si}_{1.8} \mathrm{P}_{1.2} \mathrm{O}_{12}$ (curve 7) [9], $\mathrm{Na}_{2.7} \mathrm{Sc}_{0.2} \mathrm{Zr}_{1.8} \mathrm{Si}_{1.5} \mathrm{P}_{1.5} \mathrm{O}_{12}$ (curve 8) [9], $\mathrm{Na}_{3} \mathrm{Sc}_{1.5} \mathrm{Zr}_{0.5} \mathrm{Si}_{0.5} \mathrm{P}_{2.5} \mathrm{O}_{12}$ (curve 9) [9], $\mathrm{Na}_{3.4} \mathrm{Sc}_{0.4} \mathrm{Zr}_{1.6} \mathrm{Si}_{2} \mathrm{PO}_{12}$ ) (curve 10) [2].

The obtained high conductivity may result for both structural and microstructural reasons. From a structural point of view, the large unit cell volume and the presence of two favourable Na-Na hopping distances of the monoclinic phase compared to the pure phase may contribute to the high conductivity. In the case of the microstructure, the high density, the absence of macroscopic defects such as crackformation $[8,20]$ and interfaces (grain boundaries) between the monoclinic and the rhombohedral phase with smaller intergranular resistance than in single-phase samples are regarded as reasons for the high conductivity.

\section{Lattice parameters}

The composition of the mixed-phase sample can be described as follows: the sample is composed of one NASICON structure with inhomogeneous distribution of $\mathrm{Si}$ so that two phases can be distinguished: a rhombohedral, Si-rich phase refined as $\mathrm{Na}_{3.8} \mathrm{Sc}_{2} \mathrm{Si}_{0.8} \mathrm{P}_{2.2} \mathrm{O}_{12}$ and a monoclinic, Si-free phase refined as $\mathrm{Na}_{3} \mathrm{Sc}_{2}\left(\mathrm{PO}_{4}\right)_{3}$.

$\mathrm{Na}_{3} \mathrm{Sc}_{2}\left(\mathrm{PO}_{4}\right)_{3}$ crystallizes in two modifications, high-temperature (rhombohedral, $R \overline{3} c$ ) and lowtemperature (monoclinic, $B 2 / b, C 2 / C, B b$ ) modifications, which are connected by the isotranslational relationship of these space groups [21]. For better comparison of all reported crystal structures of the $\mathrm{Na}_{3.8} \mathrm{Sc}_{2} \mathrm{Si}_{0.8} \mathrm{P}_{2.2} \mathrm{O}_{12}$ and $\mathrm{Na}_{3} \mathrm{Sc}_{2}\left(\mathrm{PO}_{4}\right)_{3}$ phases, the unit cells were transformed from 
space group $R \overline{3} c$ to $C 2 / C$. $B 2 / b$ and $B b$ settings were changed to $C$ centring using the software on the Bilbao Crystallographic Server [22,23,24]. All resulting lattice parameters are summarized in 
Table .

Both $\mathrm{Na}_{3.8} \mathrm{Sc}_{2} \mathrm{Si}_{0.8} \mathrm{P}_{2.2} \mathrm{O}_{12}$ phases in the single and mixed-phase samples have the volume per formula unit $\left(\mathrm{V} / \mathrm{Z}=\mathrm{V}_{\text {cell }} / 4\right)$. Slight differences in lattice parameters might be explained by the $10-20 \mathrm{~K}$ difference in the sintering temperatures due to the use of different furnaces. The site occupation factors (sofs) of three $\mathrm{Na}$ atoms in both structures are very close: $\operatorname{sof}_{(\mathrm{Na} 1)}=72 \%, \operatorname{sof}_{(\mathrm{Na} 2)}=67 \%, \operatorname{sof}_{(\mathrm{Na} 3)}=13 \%$ for pure $\mathrm{Na}_{3.8} \mathrm{Sc}_{2} \mathrm{Si}_{0.8} \mathrm{P}_{2.2} \mathrm{O}_{12}$ [8] compared to occupancies $70 \%, 62 \%$, and $20 \%$, respectively, for mixed-phase $\mathrm{Na}_{3.8} \mathrm{Sc}_{2} \mathrm{Si}_{0.8} \mathrm{P}_{2.2} \mathrm{O}_{12}$ (see Table 6). Our structural results (including sofs) for $\mathrm{Na}_{3} \mathrm{Sc}_{2}\left(\mathrm{PO}_{4}\right)_{3}$ correspond closely to the results of Collin, refined with space group B2/b [13]. The volume per formula unit of the compounds listed in Table 6 is plotted as a function of total $\mathrm{Na}$ amount and preparation temperature in Figure 5. There is no obvious correlation between all three parameters. However, Na-deficient ( $<3 \mathrm{Na}$ per formula unit) phases are only obtained at sintering temperatures below $1400 \mathrm{~K}$. Since the oxidation states of Sc, P, and O are fixed, the reason for Na deficiency is unclear. Aside from artefacts from the structure refinement, protons might be present thus resulting in charge-balanced formulas. 
Table 6: Lattice parameters in the equivalent monoclinic cell, number of $\mathrm{Na}$ atoms per formula unit, their occupancy and preparation temperature for $\mathrm{Na}_{3} \mathrm{Sc}_{2}\left(\mathrm{PO}_{4}\right)_{3}$ and $\mathrm{Na}_{3.8} \mathrm{Sc}_{2} \mathrm{Si}_{0.8} \mathrm{P}_{2.2} \mathrm{O}_{12}$ in the mixed-phase sample compared to the data of various single-phase materials (at $\mathrm{T}=300 \mathrm{~K}$ ). The space group and setting used in the original literature are given in brackets.

\begin{tabular}{|c|c|c|c|c|c|c|c|c|c|c|c|}
\hline & \multirow{2}{*}{ a / $\AA$} & \multirow{2}{*}{$\mathrm{b} / \AA$} & \multirow{2}{*}{$\mathrm{c} / \AA$} & \multirow{2}{*}{$\beta /{ }^{\circ}$} & \multirow{2}{*}{$\mathrm{V} / \mathrm{Z}, \AA^{3}$} & \multirow{2}{*}{$\begin{array}{c}\mathrm{Na} / \mathrm{f} . \\
\text { u. }\end{array}$} & \multirow{2}{*}{$\mathrm{T}_{\text {prep }}, \mathrm{K}$} & \multicolumn{3}{|c|}{ Occupancy, \% } & \multirow{2}{*}{ Ref. } \\
\hline & & & & & & & & Na1 & $\mathrm{Na} 2$ & $\mathrm{Na} 3$ & \\
\hline $\mathrm{Na}_{3} \mathrm{Sc}_{2}\left(\mathrm{PO}_{4}\right)_{3}(C 2 / c)$ & 15.549 & 8.982 & 9.064 & 124.73 & 260.0 & 3 & 1553 & 60 & 95 & 50 & this work \\
\hline $\mathrm{Na}_{3.8} \mathrm{Sc}_{2} \mathrm{Si}_{0.8} \mathrm{P}_{2.2} \mathrm{O}_{12}(R \overline{3} c)$ & 15.566 & 8.987 & 9.046 & 125.00 & 259.0 & 3.8 & 1553 & 70 & 62 & 20 & this work \\
\hline $\mathrm{Na}_{3.8} \mathrm{Sc}_{2} \mathrm{Si}_{0.8} \mathrm{P}_{2.2} \mathrm{O}_{12}(R \overline{3} c)$ & 15.646 & 8.996 & 9.033 & 125.43 & 259.0 & 3.8 & 1623 & 72 & 67 & 13 & [8] \\
\hline $\mathrm{Na}_{3.4} \mathrm{Sc}_{2} \mathrm{Si}_{0.4} \mathrm{P}_{2.6} \mathrm{O}_{12}(R \overline{3} c)$ & 15.554 & 8.980 & 9.041 & 124.99 & 258.6 & 3.4 & 1623 & 70 & 62 & 14 & [8] \\
\hline $\mathrm{Na}_{3} \mathrm{Sc}_{2}\left(\mathrm{PO}_{4}\right)_{3}(R \overline{3} c)$ & 15.462 & 8.927 & 9.168 & 124.21 & 261.6 & 3 & 1743 & 69 & 92 & - & [13] \\
\hline $\mathrm{Na}_{3} \mathrm{Sc}_{2}\left(\mathrm{PO}_{4}\right)_{3}(B 2 / b, B b)$ & 15.404 & 8.919 & 9.103 & 123.53 & 260.6 & 3 & fusion & 50 & 100 & 50 & [13] \\
\hline $\mathrm{Na}_{3} \mathrm{Sc}_{2}\left(\mathrm{PO}_{4}\right)_{3}(R \overline{3} c)$ & 15.502 & 8.950 & 9.034 & 124.89 & 257.0 & 3 & 1373 & 73 & 79 & - & [13] \\
\hline $\mathrm{Na}_{3} \mathrm{Sc}_{2}\left(\mathrm{PO}_{4}\right)_{3}(C 2 / c)$ & 15.641 & 8.913 & 9.016 & 124.80 & 258.0 & 2.28 & 1323 & 58 & 60 & 55 & [25] \\
\hline $\mathrm{Na}_{3} \mathrm{Sc}_{2}\left(\mathrm{PO}_{4}\right)_{3}(R \overline{3} c)$ & 15.463 & 8.927 & 9.064 & 124.66 & 257.3 & 3 & 1573 & 67 & 99 & - & [16] \\
\hline $\mathrm{Na}_{3} \mathrm{Sc}_{2}\left(\mathrm{PO}_{4}\right)_{3}(R \overline{3} c)$ & 15.469 & 8.931 & 9.054 & 124.72 & 257.0 & 2.86 & 1373 & 66 & 88 & - & [17] \\
\hline $\mathrm{Na}_{3} \mathrm{Sc}_{2}\left(\mathrm{PO}_{4}\right)_{3}(B b)$ & 16.100 & 8.928 & 9.109 & 127.15 & 259.3 & 3 & 1373 & 100 & 100 & 100 & [26] \\
\hline $\mathrm{Na}_{3} \mathrm{Sc}_{2}\left(\mathrm{PO}_{4}\right)_{3}(R \overline{3} c)$ & 15.709 & 8.936 & 9.024 & 126.01 & 256.2 & 3 & 1373 & 69 & 92 & - & [27] \\
\hline $\mathrm{Na}_{3} \mathrm{Zr}_{1.5} \mathrm{Sc}_{0.5}\left(\mathrm{Si}_{0.5} \mathrm{P}_{0.5} \mathrm{O}_{4}\right)_{3}(C 2 / c)$ & 15.616 & 9.019 & 9.184 & 123.92 & 268.3 & 3 & 1473 & 69 & 86 & 73 & [9] \\
\hline $\mathrm{Na}_{2.5} \mathrm{Zr}_{1.8} \mathrm{Sc}_{0.2}\left(\mathrm{Si}_{0.43} \mathrm{P}_{0.57} \mathrm{O}_{4}\right)_{3}(R \overline{3} c)$ & 15.560 & 8.983 & 9.219 & 124.23 & 266.3 & 2.5 & 1323 & 63 & 30 & 16 & [10] \\
\hline
\end{tabular}




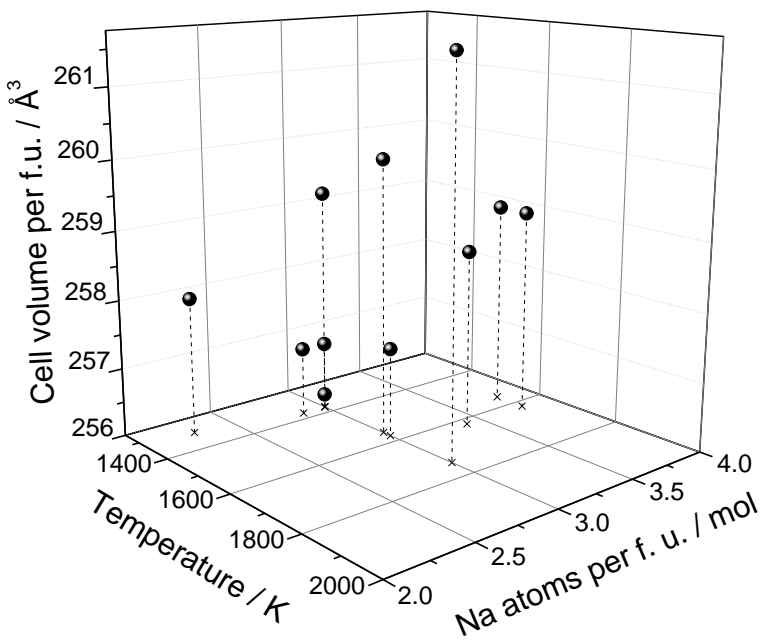

Figure 5: Volume per formula unit of $\mathrm{Na}_{3} \mathrm{Sc}_{2}\left(\mathrm{PO}_{4}\right)_{3}$ and $\mathrm{Na}_{3.8} \mathrm{Sc}_{2} \mathrm{Si}_{0.8} \mathrm{P}_{2.2} \mathrm{O}_{12}$ as a function of total number of Na per formula unit and preparation temperature of the samples.

\section{Conclusions}

$\mathrm{Na}_{3.4} \mathrm{Sc}_{2} \mathrm{Si}_{0.4} \mathrm{P}_{2.6} \mathrm{O}_{12}$ was investigated using neutron diffraction. The presence of two phases was detected and the crystallographic details of both phases were refined at $100 \mathrm{~K}$ and $300 \mathrm{~K}$. The monoclinic and rhombohedral phases have virtually the same lattice parameters (when a monoclinic cell is set up for the rhombohedral phase) and differ only in the orientation of the ( $\mathrm{P} / \mathrm{Si}) \mathrm{O}_{4}$ tetrahedra leading to a loss of symmetry in the monoclinic phase. In addition, Si was only found to be present in the rhombohedral phase refined as $\mathrm{Na}_{3.8} \mathrm{Sc}_{2} \mathrm{Si}_{0.8} \mathrm{P}_{2.2} \mathrm{O}_{12}$ whereas the monoclinic phase is $\mathrm{Na}_{3} \mathrm{Sc}_{2} \mathrm{P}_{3} \mathrm{O}_{12}$.

The high conductivity of this mixed-phase sample could be explained by the very favourable hopping distances along the different pathways for $\mathrm{Na}^{+}$conduction. Furthermore, the area of the smallest triangle of oxygen ions through which the $\mathrm{Na}$ ions have to jump is larger than the values in both single-phase materials thus allowing high conductivity.

Overall, the mixed-phase sample can be described as a sample with an inhomogeneous distribution of both $\mathrm{Si}$ and $\mathrm{Na}$. However, this inhomogeneity has little negative impact on the conductivity. Therefore it can be concluded that the unit cell volume has a major influence on the motion of the $\mathrm{Na}$ ions in the material since the size of the bottleneck for the Na conduction directly depends on the lattice parameters. A comparison of the crystal structures including literature data confirms that the correlation of the unit cell volume with $\mathrm{Na}$ content is less pronounced than the influence of the preparation route and sintering conditions, which turn out to be sensitive parameters for the optimization of materials with high ionic conductivity. 


\section{Acknowledgements}

The authors gratefully acknowledge the financial support provided by JCNS to perform the neutron scattering measurements at the Spallation Neutron Source (SNS), Oak Ridge, USA. Part of this research used resources at the Spallation Neutron Source, a DOE Office of Science User Facility operated by Oak Ridge National Laboratory.

\section{References}

[1] H. Y. P. Hong, Materials Research Bulletin, 11 (1976) 173-182

[2] Q. Ma, M. Guin, S. Naqash, C.-L. Tsai, F. Tietz, O. Guillon, Chemistry of Materials, 28 (2016) $4821-4828$

[3] S. Song, H.M. Duong, A.M. Korsunsky, N. Hu, L. Lu, Scientific Reports, 6 (2016) 32330

[4] K. M. Abraham, R. D. Rauh, S. B. Brummer, Electrochimica Acta 23 (1978) 501-507

[5] F. Lalère, J.B. Leriche, M. Courty, S. Boulineau, V. Viallet, C. Masquelier, V. Seznec, Journal of Power Sources, 247 (2014) 975-980

[6] M. Guin, F. Tietz, Journal of Power Sources, 273 (2015) 1056-1064

[7] R. D. Shannon, Acta Crystallographica, A32 (1976) 751-767

[8] M. Guin, F. Tietz, O. Guillon, Solid State Ionics, 293 (2016) 18-26

[9] M. A. Subramanian, P. R. Rudolf, A. Clearfield, J. Solid State Chem. 60 (1985) 172-181

[10] P. J Squattrito, P. R. Rudolf, P. G. Hinson, A. Clearfield, K.Volin, J. D. Jorgensen, Solid State Ionics, 31 (1988) 31-40

[11] V. Petricek, M. Dusek, L. Palatinus, Zeitschrift für Kristallographie, 229 (2014) 345-352

[12] V. F. Sears, Neutron News, 3 (1992) 26-37

[13] G. Collin, R. Comes, J. P. Boilot, P. Colomban, Journal of Physics and Chemistry of Solids, 47 (1986) 843-854

[14] H. Y. P. Hong, J. B. Goodenough, J. A. Kafalas, Materials Research Bulletin, 11 (1976) 203-220

[15] V. V. Tkachev, V. I. Ponomarev, L. O. Atovmyan, Journal of Structural Chemistry 25 (1984) $111-116$

[16] J. M.Winand, A. Rulmont, P. Tarte, Journal of Materials Science, 25 (1990) 4008-4013

[17] A. Nogai, V. B. Kalinin, S. Yu. Stefanovich, Yu. N. Venevtsev, Russian Journal of Inorganic Chemistry (Engl. Transl.), 30 (1985) 1674-1677

[18] L. Boehm, C. J. Delbecq, E. Hutchinson, S. Susman, Solid State lonics 5 (1981) 311-314

[19] S. Susman, C. J. Delbecq, T. O. Brun, E. Prince, Solid State lonics 9 \& 10 (1983) 839-844

[20] V. Srikanth, E. C. Subbarao, D. K. Agrawal, C.-Y. Huang, R. Roy, Journal of the American Ceramic Society 74 (1991) 365-360

[21] M. I. Aroyo, International Tables for Crystallography, Departamento Fisica de la Materia Condensada, Universidad del Pais Vasco, UPV/EHU, Bilbao, Spain, 2013 
[22] M. I. Aroyo, J. M. Perez-Mato, D. Orobengoa, E. Tasci, G. de la Flor, A. Kirov, Bulgarian Chemical Communications, 43 (2011) 183-197

[23] M. I. Aroyo, J. M. Perez-Mato, C. Capillas, E. Kroumova, S. Ivantchev, G. Madariaga, A. Kirov, H. Wondratschek, Zeitschrift für Kristallographie, 221 (2006) 15-27

[24] M. I. Aroyo, A. Kirov, C. Capillas, J. M. Perez-Mato, H. Wondratschek, Acta Crystallographica, A62 (2006) 115-128

[25] H. Y. P. Hong, in: Proc. Int. Conf. Fast Ion Transport in Solids (1979), eds. P. Vashishta, J. N. Mundy, G. K. Shenoy, Elsevier North Holland, Inc.

[26] V. A. Efremov, V. B. Kalinin, Kristallografiya, 23 (1978) 703-708

[27] I. Sotøfte, D.-Ch. Fu, Solid State Ionics 26 (1988) 307-310 